\title{
Repasando la frontera hispano-portuguesa: Conflicto, interacción y cooperación transfronteriza
}

\section{Reviewing the Spanish-Portuguese border: Conflict, interaction and cross-border cooperation}

\author{
Francisco José Calderón Vázquez*
}

Resumen

Las fronteras europeas y, muy específicamente, las fronteras entre Estados miembros de la Unión Europea constituyen productos históricos "vivos" que personifican las vicisitudes de los territorios fronterizos europeos en constante evolución: desde un pasado de luchas y enfrentamientos entre las diferentes unidades sociopolíticas europeas, hasta un futuro de progresiva integración comunitaria. Tales procesos de desactivación fronteriza resultan de gran complejidad. En la presente contribución, analizamos el caso de la frontera hispano-portuguesa, revisando su evolución desde la perspectiva de la interacción transfronteriza.

Palabras clave: fronteras, cooperación transfronteriza, fronteras europeas internas, interacciones fronterizas, desactivación fronteriza.
Abstract

European borders, or borders between European Union member states, are historical products that embody the ebbs and flows of European borderlands. These areas are evolving from past struggles and confrontations between European kingdoms toward a future of progressive European integration. Such processes are highly complex, as they involve border deactivation. In this work, we examine the evolution of the SpanishPortuguese border from the perspective of cross-border interaction.

Keywords: borders, cross-border cooperation, European Union internal borders, border interactions, border deactivation.

Recibido: 18 de diciembre de 2013.

Aprobado: 19 de septiembre de 2014.

* Universidad de Málaga, Facultad de Ciencias Económicas, Departamento de Economía Aplicada. Dirección: 4ª Planta, Despacho 4110, Campus del Ejido s/n, C.P. 29071, Málaga, España. Correo electrónico: fjcalderon@uma.es 
Introducción. Fronteras europeas: de la separación a la integración

Consideradas por algunos como "cicatrices de la historia" (De la Fuente, 2009, pp. 115-130) y por otros como "tiempo escrito en el espacio" (Kavanagh, 2009, pp. 155-172), las fronteras han constituido un elemento crítico en la configuración del Estado-nación puesto que el confín diferencia, aísla, protege y separa a dicho Estado de los restantes. En este sentido, el "territorio nacional" se define por sus fronteras, visualizándose como un espacio territorial hermético e impermeable, soporte territorial y físico de la unidad socio-política allí radicada, planteándose de este modo una conexión, casi indisoluble, entre frontera, Estado y nación (Donnan, 1998; Donnan y Wilson, 1994 y 1999; Taylor, 1994 y 1995).

Como tal línea de demarcación, el resultado tangible de la delimitación de una frontera es la discontinuidad o diferencial (jurídico, político, económico-fiscal-aduanero, lingüístico-étnico-cultural, etc.) que se produce entre ambos lados del confín: al pertenecer dichos territorios limítrofes a ordenamientos legales, sociales, económicos y sistemas políticos diferentes (Cairo, 2001; Foucher, 1991). Precisamente, es en la discontinuidad (y en sus consecuencias económicas, legales y culturales) donde radicaba el principal factor de preocupación de los primeros economistas regionales hacia la temática fronteriza (Christaller, 1966; Lösch, 1967), considerándose la delimitación fronteriza como una forma de fragmentación o separación de territorios contiguos. Introduciéndose con la frontera, barreras artificiales que tienden a aislar a dichos territorios de sus adyacentes, fraccionando el mercado existente e impidiendo la complementariedad productiva y territorial. Al desestimularse la inversión en dichos territorios, se obstaculizaba su desarrollo económico.

Con la paulatina expansión de la globalización (y de la subsiguiente economía global), la visión decimonónica de la frontera como muralla defensiva de separación y borde exterior del Estado-nación, va perdiendo progresivamente sentido, dejando paso a una visión de la frontera como puente, configurándose los territorios fronterizos como tales zonas de interacción, conexión y cooperación entre territorios y comunidades contiguos (Bradshaw y Linares, 1999; Kolossov y O’Loughlin, 1998; Newman, 1998; Newman y Paasi, 1998), surgiendo la narrativa transborder 
o transfronteriza (Lezzi, 1994). Desde dicha perspectiva, las áreas fronterizas constituyen la plataforma idónea para la maximización de intercambios de todo tipo entre los dos lados del confín. En el peculiar marco territorial de la Unión Europea (UE), las fronteras entre los diferentes Estados miembros constituían un obstáculo muy importante en el proceso de integración económica europea, por lo que su desactivación era un objetivo fundamental para la construcción del Mercado Único Europeo, germen de la actual Eurozona y de su expresión política, la Unión Europea.

Por ello, durante las cuatro últimas décadas, el discurso europeísta referido a las fronteras entre Estados miembros o intracomunitarios se ha movido, clara y rotundamente, en las coordenadas del discurso transborder (Lofgren, 2008; Sideway, 2001), insistiendo en la consideración de las fronteras intraeuropeas como "espacios de intersección y cooperación" (Cairo, Godinho y Pereiro, 2009; Comisión Europea, 2007). Consideración que no se extiende a las fronteras externas o exteriores de la UE, en las que permanece, en lo básico, la visión primaria de "barrera defensiva", caso de las fronteras comunitarias con Marruecos (Cairo, 2009; Ferrer, 2007 y 2008), Rusia, Bielorrusia o Ucrania.

En su evolución, la narrativa europea sobre el hecho fronterizo ha transitado desde la consideración de las fronteras como zonas periféricas o marginales, "difíciles" de desarrollar en términos socioeconómicos y, por tanto, necesitadas de estímulos económicos de todo tipo (Tamames, 1994), hasta la visión de las fronteras europeas como zonas "bisagra" o de articulación territorial, desde donde impulsar el proyecto de integración económica europea (De la Fuente, 2009). Así, en la perspectiva de la integración europea, las zonas fronterizas intracomunitarias debían constituir uno de los pilares fundamentales de dicho proceso integrador, al disponer los territorios fronterizos y sus poblaciones de la experiencia del contacto cotidiano con los "otros" europeos (Van Houtum y Strüver, 2002).

En este contexto tan favorable a la interacción, la cooperación transfronteriza ${ }^{1}$ va a constituir el instrumento fundamental para llevar a cabo

${ }^{1}$ Definida en el art. 2 del Convenio Marco Europeo de Cooperación Transfronteriza, como "toda acción concertada tendente a reforzar y a desarrollar las relaciones de vecindad entre comunidades o autoridades territoriales pertenecientes a dos o varias partes contratantes, así como a la conclusión de los acuerdos y arreglos convenientes 
dichos fines, estableciéndose una serie de mecanismos institucionales para su regulación. ${ }^{2}$ Asimismo, los poderosos estímulos económicos ofrecidos por la Política Regional Europea, en particular por el Fondo Europeo de Desarrollo Regional (FEDER), junto a la creación y desarrollo de instrumentos económicos específicos para las zonas fronterizas, como Innovation E Environment Regions of Europe Sharing Solutions (INTERREG), van a generar un clima muy proclive a la actuación inversora en dichas áreas. Actuaciones complementarias de las anteriores pero muy relevantes en el plano sociopolítico, ha sido la generación de las denominadas Eurorregiones, ${ }^{3}$ con la creación de la Eurorregión Mosa-Rhin (1976), primera de una larga serie. ${ }^{4}$

En este marco de progresiva desactivación del hecho fronterizo dentro de la Unión Europea, la frontera hispano-portuguesa aparece como una de las fronteras intraeuropeas más longevas, extensas y estables de Europa (Kavanagh, 2009; López, 2005), una frontera que encarna las características comunes a muchos territorios fronterizos europeos y refleja las vicisitudes de su proceso evolutivo, pasando desde un pasado remoto, marcado por conflictos y luchas, en este caso entre los dos grandes reinos ibéricos, hasta un presente esperanzador, caracterizado por las abundantes iniciativas de cooperación transfronteriza y la mayor sintonía entre las poblaciones y las economías de la frontera luso-española.

A lo largo de sus más de siete siglos de existencia y sus $1234 \mathrm{~km}$ de recorrido, la frontera luso-hispana ha desempeñado un catálogo de funcionalidades territoriales muy diverso y cambiante, desde las tradicionales (militares, defensivas, comerciales, etc.) hasta las actuales, como tal frontera intraeuropea, actuando como soporte territorial de la cooperación transfronteriza, umbral de paso para los flujos de bienes, personas, mercancías, servicios y capitales, fundamentales en el momento actual.

a tal fin” (Asociación de Regiones Fronterizas Europeas [ARFE], 1997; Consejo de Europa, 1980).

2 Tanto el cmect (1980) como la Carta Europea de Cooperación Fronteriza (1974) responden a esta finalidad. Ambos instrumentos normativos van a ser promovidos por el Consejo de Europa y la ARFE, verdaderos dinamizadores del fenómeno transborder en Europa.

${ }^{3}$ Figura jurídico territorial orientada a estructurar la cooperación transfronteriza entre dos o más países europeos.

${ }^{4}$ Contándose en la actualidad 67 eurorregiones. 
En el presente trabajo revisamos la trayectoria de la frontera hispano-lusa, enclave de interacción transfronteriza, abarcando las diferentes tipologías interactivas desde las conflictivas hasta las pacíficas (como las humanas, culturales, socioeconómicas y estatales) que en la misma han tenido lugar, describiéndose el cambio de tendencia que, desde 1992, ha supuesto la llegada de la cooperación transfronteriza a una frontera como la luso-hispana no demasiado proclive a este tipo de relación. La consolidación de la misma como modus actuandi cotidiano, constituye el hecho de nuestro tiempo en la frontera más longeva de Europa. Hecho que no está exento de contradicciones, fallos, ambigüedades o voluntarismos que en algunos momentos del texto señalamos y que en el apartado cuarto glosamos.

A tales efectos, el texto se ha estructurado después de esta introducción, en tres secciones más. En la primera, revisamos las interacciones tradicionales existentes en la frontera luso-hispana, distinguiendo cuatro grupos: interacciones conflictuales y cooperativas; hibridaciones fronterizas tanto culturales como humanas; interacciones socioeconómicas, lícitas o ilícitas; y la peculiar matriz de relaciones estatales hispano-portuguesas, "a costas voltadas".

En la sección dos, se describe, por una parte, el proceso de despliegue del cross-border luso-hispano y sus primeros resultados, incidiendo en el papel de los programas comunitarios, en particular INTERREG, como dinamizadores de la inversión, aportándose algunos datos cuantitativos relevantes. Por otra parte, describimos el nuevo instrumento comunitario de política regional, financiador de la cooperacion transfronteriza hispano lusa, el denominado Programa Cooperación Transfronteriza España-Portugal (POCTEP) 2007-2013, situándolo en el contexto político-institucional de la UE, y además, indicamos sus principales características y las aportaciones financieras previstas.

En la última sección, se procede a la elaboración de conclusiones y reflexiones. En la configuración del texto hemos procurado, en todo momento, mantener un equilibrio entre las fuentes bibliográficas portuguesas e hispanas, esfuerzo que esperamos tenga su recompensa. 
Francisco José Calderón Vázquez / Repasando la frontera hispano-portuguesa

\section{Las interacciones fronterizas tradicionales luso-hispanas}

\section{La frontera luso-hispana: Orígenes y configuración}

La "Raya Ibérica" se gesta a través de los siglos, configurándose a partir de los Tratados de Zamora (1143), Badajoz (1267) y Alcañices (1297), pactos que delimitan, en lo esencial, la frontera tal y como la conocemos en nuestros días. Aunque será con la firma del Tratado de Lisboa (1864), ${ }^{5}$ complementado por el Acuerdo de Límites (1926), ${ }^{6}$ cuando se llegue al trazado actual.

En el origen y configuración de la frontera hispano-portuguesa aparece con nitidez la voluntad de los emergentes reinos portugués y castellano de establecer sus confines (y sus áreas de influencia), de modo cierto, tajante y verificable (Calderón, 2010). En el caso portugués, la fijación de fronteras suponía su afianzamiento como entidad política soberana respecto de su poderoso y agresivo vecino castellano, de ahí que la frontera aparezca como vehículo decisivo en la construcción de la identidad nacional lusa, al ser el instrumento que garantice su seguridad e integridad territorial.

No es extraño, por tanto, que la flamante "identidad portuguesa" aparezca impregnada de evidente sesgo anti-castellano y, por extensión, antiespañol (Cairo, Godinho y Pereiro, 2009). Asimismo, de la fijación de la raya luso-castellana se derivan unas áreas de influencia distintas en los ámbitos cultural, lingüístico e identitario, constituyéndose en elementos diferenciadores básicos de cada zona fronteriza (en contraposición con la opuesta limítrofe), su lengua, su "cultura" y su "identidad".

\section{Interacciones conflictuales: Tierra de nadie}

Como tal barrera defensiva, la Raya Ibérica actuó, desde sus orígenes, como espacio de encuentros y de desencuentros (Antunes, 2008; Medina,

${ }^{5}$ Tratado de Límites de 29 de septiembre de 1864, que abarca desde la desembocadura del Miño hasta la unión del río Caya con el Guadiana entre España y Portugal.

${ }^{6}$ Acuerdo del 29 de junio de 1926, entre España y Portugal, que delimita la frontera entre ambos países desde la confluencia del río Cuncos con el Guadiana hasta la desembocadura de éste con el mar, ratificado el 17 de junio de 1927 (Gaceta del 29 de junio de 1927). 
2006), campo de batalla y tierra de nadie entre los reinos de Castilla y Portugal, los cuales dirimían sus disputas en dicho territorio. Ello explica la abundancia y el relieve de las instalaciones militares a uno y otro lado de la raya; ${ }^{7}$ estas fortalezas operaban como atalayas desde las que se vigilaban y contrarrestaban los movimientos del enemigo, tratando de cerrar el paso a potenciales invasiones.

La presencia de estas fortificaciones y baluartes acentuó de manera notable el uso militar defensivo-ofensivo del territorio, provocando la consiguiente despoblación de las tierras fronterizas, dada la inseguridad existente. Este hecho va a influir notablemente en el carácter territorial periférico o ultraperiférico de las áreas fronterizas hispano-portuguesas.

La secuencia de enfrentamientos bélicos entre Portugal y Castilla comienza en 1247, continuando hasta 1801, siendo especialmente virulentos durante la Guerra de la Independencia de Portugal (1640-1668) y la Guerra de Sucesión Española (1703-1714), devastándose y despoblándose amplias zonas fronterizas (Medina, 2006). Encarnación de los conflictos fronterizos hispano-lusitanos, serán las zonas territoriales disputadas por ambos contendientes, denominadas Contiendas ${ }^{8}$ o Reyertas ${ }^{9}$ (Martín, 2003), zonas indefinidas en cuanto a su "identidad", que no pertenecían oficialmente a ninguno de los dos países. Esa condición "mixta” las hacía inmunes (e impunes) a la justicia española y portuguesa, que no podían ni penetrar ni perseguir, en dichas zonas, a los fugados de la justicia, delincuentes, desertores, etcétera, existiendo la tradición consuetudinaria del asilo en tales enclaves, situación que se prolongó hasta la segunda mitad del siglo xviri. Ante tal situación de indefinición, el Tratado de Lisboa de 1864 (United Nations, 1982, p. 250) adoptará una actitud salomónica, asignando las zonas en litigio a cada uno de los litigantes de la manera más paritaria posible, tratando de contentar a ambos. ${ }^{10}$ Como la satisfacción

\footnotetext{
${ }^{7}$ Como los baluartes portugueses de Almeida, Elvas, Estremoz, Campomaior, Marvão, Castelo de Vide, Évora, Monsaraz contrapuestos a las fortalezas españolas de Ciudad Rodrigo, Olivenza, Badajoz, el Fuerte de la Concepción o los castillos de Alburquerque, Alconchel y Valencia de Alcántara.

${ }^{8}$ Como la "Contienda de Moura" y la "Contienda de Olivenza".

${ }^{9}$ Como las de "Valencita" o Valencia de Mombuey, la de "Villanueva del Fresno", la de "Alconchel" o la de "Barcarrota".

${ }^{10}$ De este modo, el artículo xxiI de dicho tratado optará en dividir por mitades el territorio de las Reyertas, atribuyendo dichas medias partes respectivas a cada Estado. Así,
} 
Francisco José Calderón Vázquez / Repasando la frontera hispano-portuguesa

de las partes no resultaba plena, las zonas indefinidas no resueltas por el tratado tuvieron que esperar hasta 1893 para su asignación definitiva, realizada por la Comisión de Límites (1926). ${ }^{11}$

Interacciones humanas, sociales y culturales: Hibridaciones, mestizajes y complicidades

En paralelo a la frontera de separación y exclusión entre los Estados ibéricos, había un espacio fronterizo de interacción y contacto entre las personas situadas a uno y otro lado de la línea fronteriza. Es decir, la Raya, además de barrera era umbral de interacciones humanas y comerciales entre las personas de uno y otro lado del confín, actuando como espacio de convergencia y cooperación donde cotidianamente confluían las poblaciones rayanas. Se trataba de una frontera de convivencia y complicidad, derivada de las acuciantes necesidades cotidianas, a pesar de las directrices estatales (Medina, 2006; Antunes, 2008). Esa interacción cotidiana se ha manifestado en fenómenos de hibridación cultural, ósmosis social e intersección económica y comercial.

\section{Hibridaciones socio-culturales: Falas, povos y coutos}

En su dimensión lingüística, la hibridación cultural se encarna en las denominadas "hablas fronterizas" o lenguas de transición entre el portugués y el español, como los dialectos "barranqueño", "fala”, "mirandés", presentes en determinados enclaves limítrofes (Medina, 2006), a los que habría que añadir el "riodonorés", en la zona fronteriza zamorana y los

la Reyerta de Onguella se dividirá en dos: la Reyerta de Arriba, que se atribuirá a Portugal, y la de Abajo, que se atribuirá a España. Mientras que la Reyerta de Arranches será dividida por tercios, atribuyéndose a España las dos terceras partes, quedando el tercio restante para Portugal.

${ }^{11}$ La Comisión de Límites asignó por mitades la denominada "Dehesa de la Contienda", una zona indelimitada de $123 \mathrm{~km}^{2}$ de superficie, atribuyendo una mitad a los concelhos portugueses de Barrancos y Moura (Portugal) y la otra a los municipios onubenses de Aroche y Encinasola. 
dialectos de Cedillo y Herrera de Alcántara en la frontera de Cáceres (Carrasco, 1997).

Los fenómenos de hibridación social y humana luso-hispana aparecen personificados, por una parte, en las migraciones transfronterizas como las de comunidades hispanas en tierras lusas (el caso de Barrancos) o los casos de comunidades lusas en tierra hispana (casos de Taliga y Olivenza). Por otra, en las peculiares figuras territoriales denominadas por el Tratado de Lisboa en 1864, como Povo Promíscuo y Couto Misto. En el caso de los "povos promíscuos", ${ }^{12}$ localidades en situación de ambigüedad o indefinición respecto de su "vinculación nacional" ya fuese a España o Portugal (United Nations, 1982, p. 247), tales enclaves, hasta 1864 "indefinidos", pasarán a formar parte de Portugal desde esa fecha (García, 1998).

El Couto Misto, una suerte de "tierra de nadie" fronteriza entre España y Portugal, con una superficie aproximada de $27 \mathrm{~km}^{2}$ y una población que no alcanzaba el millar de habitantes, estaba integrado por tres núcleos de población (Santiago, Rubiás y Meaus) actualmente bajo soberanía española, situados al sur de Orense (García, 1998).

La peculiaridad del Coto Misto radicaba en su amplia autonomía, casi "soberanía", frente a ambas coronas ibéricas, disponiendo de un particular statu quo (United Nations, 1982, p. 246), traducido en autogobierno ("Leyendas y curiosidades", 2005), ya que sus habitantes elegían alcalde y jueces propios, supervisados conjuntamente por el obispo de Orense y el administrador civil de Braga. Asimismo, esa "soberanía mixta" significaba una serie de privilegios "notorios" para sus habitantes en relación con sus vecinos inmediatos lusos o hispanos ("Leyendas y curiosidades", 2005), como la exención del servicio militar, exención de impuestos, libertad de comercio de determinados productos "estancados" en ese tiempo (como la sal), la libertad de cultivos (como el tabaco) o la libre elección de nacionalidad española o portuguesa al casarse (García, 1998).

También disfrutaba el Coto Misto del derecho de asilo para prófugos de la justicia (Cairo, 2009; Kavanagh, 2009), ya fuera la lusa, ya la española (García, 1988). Incluso disponía de un "camino privilegiado" que discurría entre territorio español y portugués por el que sus habitantes podían

${ }^{12}$ En el texto del tratado aparecen los povos promiscuos de Soutelinho, Cámbedo y Lama-Darcos, núcleos situados prácticamente sobre la línea fronteriza, entre los municipios españoles de Oimbra y Verín y el Concejo portugués de Chaves. 
comerciar y transitar, resultando inviolable para las respectivas guardias fronterizas.

Como otras manifestaciones de esa ambigüedad fronteriza hispanolusa, en el ámbito humano y social, se cuentan los denominados "núcleos gemelos", es decir, pueblos o caseríos que tienen una vertiente lusa y otra hispana. ${ }^{13}$ Igualmente, podrían incluirse dentro de esa dualidad fronteriza "portuñola", las localidades que mutaron su nacionalidad, caso de San Felices de los Gallegos, antaño pueblo portugués.

Finalmente, podríamos citar como núcleos "particularmente ambiguos", a los que por encontrarse en lugares muy accidentados de la línea fronteriza han vivido en la dualidad, prácticamente hasta nuestros días, caso de las llamadas "Casas de la Duda", un pequeño caserío situado en la misma raya entre Valencia de Alcántara (Cáceres, España) y Portalegre (Alto Alemtejo, Portugal), cuyos habitantes, al ser “dudosos”, podían optar entre empadronarse en Valencia de Alcántara o en Portalegre, decantándose, de esta manera, por una u otra nacionalidad (Rubio, 2007; "Curiosidades", 2012).

\section{Interacciones económicas y comerciales}

En el campo económico, la interacción fronteriza tradicional se ha manifestado en diversos campos; por una parte, los usos y aprovechamientos comunes de los recursos naturales, práctica de claro origen consuetudinario bastante frecuente a lo largo de La Raya, como los aprovechamientos conjuntos de pastizales y labrantías entre Rionor (España) y Rio d'Onor (Portugal) ("Un país", 2006). Otros campos fundamentales de interacción económica transfronteriza secular han sido tanto los tráficos comerciales lícitos (comercio local fronterizo) como los ilícitos (el contrabando).

El contrabando resulta, sin lugar a dudas, la fuente (Duarte, 1998) de interacciones más sustantiva en la economía fronteriza de La Raya, puesto que esta forma de trasgresión ha constituido una realidad sustantiva e histórica

${ }^{13}$ Como serían los casos del luso Río d'Onor (Tras os Montes, Portugal) y del hispano Rionor (Zamora, España), o el caso de los caseríos de Marco (Portalegre, Portugal) y El Marco (La Codosera, Badajoz, España), Rabaça (Portalegre, Portugal) y la Rabaza (La Codosera, Badajoz, España). 
de estas tierras (Duarte, 1998; Melón, 1999), que va mas allá de lo puramente económico para convertirse en una verdadera "forma de vida" (Cabanas, 2006b; Cáceres y Valcuende, 1996; Cruz-Sagredo, 2010; Freire, 2001; Kavanagh, 2009; Medina, 2004; Pinheiro, 2004). Una forma de vida alternativa o complementaria a la actividad agropecuaria y a las actividades "jornaleras" en las grandes haciendas, necesaria (si no imprescindible) para la gran mayoría de los habitantes de La Raya, vista sus pobres (o míseras) condiciones de vida, unida a la falta de horizontes (Antunes, 2008; Cabanas, 2006b; Cruz-Sagredo, 2010).

El contrabando rayano fue una actividad de gran efecto social, dadas las "redes sociales" necesarias para poder llevarlo a cabo. Redes que implicaban a numerosas "cuadrillas" y a muchos individuos en los pueblos fronterizos con importante participación femenina, contando además con la imprescindible connivencia (cuando no complicidad) de gran parte de la población fronteriza, junto al evidente "mirar al otro lado" de los poderes administrativos y policiales a ambos lados de la frontera. Parece pues lógico que "la práctica del contrabando era una actividad culturalmente aceptada" (Cabanas, 2006a; Freire, 2001; Kavanagh, 2009, p.164; Pinheiro, 2004). El contrabando en La Raya incluso podría considerarse como un canal de comercialización alternativo al mercado tradicional, puesto que la salida de la producción de las manufacturas portuguesas torrefactoras de café (Medina, 2004), se realizaba mediante cuadrillas especializadas, dedicadas íntegramente a tales tareas, consolidándose el contrabando como vehículo de exportación a gran escala. En este sentido, Kavanagh (2009) cita la exportación (de contrabando) del wolframio ${ }^{14}$ portugués, pasándose el mineral a España y exportándose lícitamente desde territorio español hacia Alemania durante la Segunda Guerra Mundial.

Por lo que se refiere al no menos secular comercio fronterizo de pequeña dimensión, referido a los intercambios de conveniencia y necesidad entre las pequeñas localidades contiguas situadas a uno y otro lado de La Raya (De la Montaña, 2005), éste va a conocer una etapa de cierta expansión en el periodo (1890-1980): si bien con la desaparición de los controles fronterizos de personas y mercancías (Carrasco, 2001) y el desarrollo de las infraestructuras de transporte y comunicación transfronterizas (con la

\footnotetext{
${ }^{14}$ También llamado “tungsteno”, usado para galvanizar el acero del material militar.
} 
subsiguiente aceleración de los flujos de transporte), se observa una evidente regresión en el mismo (Kavanagh, 2009), hipotizándose su posible desaparición en los próximos años.

\section{Relaciones interestatales: As costas voltadas}

Hasta la adhesión formal de Portugal y España a la Comunidad Económica Europea (CEE) en 1986, podemos describir las relaciones interestatales entre ambos Estados ibéricos como un vivir as costas voltadas, es decir, dándose la espalda (Reis, 2007), consecuencia de ese peculiar entramado de desconfianzas existente entre los dos grandes Estados ibéricos, quienes como modus operandi habitual tendían a "vivir a espaldas del vecino" (López, 2005). Pero ese "as costas voltadas" va mas allá de una sugestiva metáfora que designa una situación de recíproca ignorancia, puesto que va a sintetizar, en una frase, toda esa sucesión de encuentros y desencuentros que han caracterizado las interacciones estatales hispano-portuguesas (Fonte, 2007).

Tan cerca pero tan lejos; portugueses y españoles, formalmente amigos, pero de facto poco proclives a la interacción, vivían enrocados, cada uno en su lugar, por lo que la potencial "aproximación" entre posiciones, tan ambiguas y "distantes", no estaba exenta ni de dificultades ni de prejuicios históricos (Kavanagh, 2009 y 2011).

El detonante del cambio, ciertamente histórico, estará en la incorporación de ambos países ibéricos al Mercado Único Europeo, lo que conllevará el desmantelamiento de las aduanas y, posteriormente, a la Europa de Schengen (1992), que traerá el libre tránsito de un país al otro. Esta sucesión de innovaciones sociales en un breve periodo (1986-1992) provocaría un giro copernicano en la dinámica fronteriza, hasta ese momento muy limitada, en el conjunto de la frontera luso-hispana y en el comercio fronterizo (y el contrabando). Con excepción de los grandes ejes viarios de comunicación, ${ }^{15} \mathrm{y}$ de tales ejes fronterizos y de los mercados locales

${ }^{15}$ De sur a norte de la frontera: Ayamonte (España)-Vilar Real do Santo Antonio (Portugal); Badajoz (España)-Elvas-Campo Maior (Portugal); Fuentes de Oñoro (España)Guarda (Portugal), situado en la N-620, una de las principales vías de comunicación entre Portugal-España-Francia; Verín (España)-Chaves (Portugal), Tuy (Pontevedra, 
situados en la linde fronteriza o en sus cercanías (Valença do Minho, Miranda do Douro, Vilar Formoso, Elvas, Vila Real, etc.), el conjunto de La Raya Ibérica no se caracterizó por actuar como soporte de intercambios, a diferencia de otras fronteras centro-europeas mucho más orientadas a la cooperación, como la belga-holandesa, la holandesa-alemana, o el propio Benelux (Bélgica, Holanda y Luxemburgo). Por el contrario, la luso-hispana se encontraba mucho más escorada hacia la "no cooperación" (Caramelo, 2002; García Flores y Mora Aliseda, 2005; Gaspar, 1993), resultado, por una parte, de la propia estructura económica de la inmensa mayoría de los tramos fronterizos (y su anexa configuración socioeconómica) como periferias o ultraperiferias continentales agro-silvo-pastorales (Calderón, 2010; López, 2005), con pocos centros urbanos dinámicos y relevantes, meros productores de materias primas, de población mayoritariamente rural escasa y dispersa, de muy bajo nivel adquisitivo, con altos niveles de pobreza (De la Macorra, 2005). Esa escasa solvencia de la demanda, unida (o mejor, combinada) a las "costas voltadas", provocará esa tendencia a la no cooperación o a la cooperación meramente local-rayana, situación que parece hundir sus raíces en la historia (Hinojosa, 1998), aunque según Medina (2008), la polémica existente y las posiciones divergentes al respecto resultan notables (Melón, 1999; Val Valdivieso, 1987).

\section{La llegada de la cooperación transfronteriza. La política de cooperación transfronteriza en el contexto institucional de la UE}

\section{La cooperación transfronteriza en La Raya Ibérica. El papel de INTERREG}

Las innovaciones socio-institucionales anteriormente consideradas, provocarán un cambio de rumbo muy significativo en la vida de la frontera y de su gente, abriéndose una nueva etapa de cooperación y acercamiento

España) y Valença do Minho (Viana do Castelo, Portugal), ejes que siempre han mantenido el tono comercial y de intercambio, acentuándose mucho su importancia en la jerarquía territorial fronteriza (población, niveles de actividad económica, etc.) tras la "revolución" en las interacciones de todo tipo (económicas, culturales, turísticas, etc.) que ha tenido lugar entre ambos países desde 1992. 
entre "vecinos", tradicionalmente no demasiado bien avenidos (Medina, 2009) a partir de 1992. El cambio del clima relacional luso-hispano se irá traduciendo lentamente en una actitud más proclive al entendimiento con el "otro" y a la interacción con el mismo, generándose una mayor fluidez en las relaciones transfronterizas, ya desde los gobiernos centrales luso e hispano, ya desde las administraciones regionales y locales (aunque estas últimas siempre hayan estado interesadas en lo transfronterizo), constituyendo la frontera hispano-lusa, desde 1996 en adelante, punto de partida de numerosas iniciativas de cooperación transfronteriza ${ }^{16}$ (Castro, 2011; Medina, 2009; Pires y Pimentel, 2004;), abarcando tales iniciativas una amplia gama de contenidos temáticos que van desde lo empresarial a lo cultural, lo lingüístico y lo turístico, pasando por lo administrativo, lo medioambiental y la gestión del territorio fronterizo.

La gestión de dichas iniciativas ha dado lugar a la aparición de nuevas "instituciones transfronterizas" para la administración de los programas e iniciativas transfronterizas, como los denominados "Gabinete de Iniciativas Transfronterizas" (Corrales, 2006), las comisiones de coordinaciones transfronterizas, o las asociaciones transfronterizas, ${ }^{17}$ destinadas a la dinamización de los espacios de frontera luso-hispanos, mediante la propuesta de proyectos e iniciativas a financiar por los fondos y programas europeos (Medina, 2009).

Además, se ha producido un incremento evidente de los flujos comerciales entre ambas partes, habiéndose — por ejemplo—, doblado las cifras de importación y exportación luso-hispanas (Medeiros, 2011). Igualmente, se observa una mayor presencia física de españoles y portugueses al otro lado de la línea de frontera, ya en términos de conocimiento enogastronómico y ambiental del territorio del "otro" (Castro, 2011), ya en términos de inversión, oportunidades de negocio y comerciales (Antunes, 2008; Corrales, 2006), aunque se haga necesario precisar que, en términos macro, la enorme expansión observada en la inversión española en tierras lusas, parezca haber "tocado" poco a las zonas fronterizas, concentrándose

\footnotetext{
${ }^{16}$ Entendida ésta, según Eusebio Medina (2009), como modalidad relacional habitual y cotidiana entre ambos lados de la frontera. Modalidad "ordinaria" y no extraordinaria. ${ }^{17}$ En este sentido, adquiere especial importancia la Agrupación Europea de Cooperación Territorial (AECT), aparecida en 2006 para favorecer la creación de redes de actores y la gestión de proyectos comunes transfronterizos.
} 
en las zonas centrales del país lusitano (Pires y Teixeira, 2002), por lo general zonas metropolitanas y urbanas, si bien se observa un esperanzador incremento de proyectos inversores españoles en algunos municipios fronterizos portugueses (Pires y Teixeira, 2003). Asimismo, el número de empresas lusas operando en suelo hispano todavía resulta muy reducido, aunque se haya incrementado notablemente su volumen en relación con épocas pasadas (Medeiros, 2009).

Este "florecimiento" de las iniciativas de cooperación transfronteriza luso-hispanas parece tener mucho que ver con las generosas oportunidades de financiación ofrecida por los Fondos Estructurales Comunitarios (FEDER, Fondo Europeo de Orientación y Garantía Agrícola [FEOGA], el Fondo de Cohesión, etc.), junto a las (no menos generosas) iniciativas y programas comunitarios, en particular INTERREG ${ }^{18}$ y, en menor medida, el programa Liaisons entre activités de Developement de L'Economie Rural (LEADER). ${ }^{19}$

En lo referente a INTERREG, esta iniciativa comunitaria ha desempeñado un papel de dinamizador financiero e inversor muy significativo en las zonas fronterizas hispano-portuguesas, en sus diferentes programas plurianuales, poniendo a disposición de las mismas los siguientes recursos financieros: el Programa inTerReg iI (1994-1999) financió con 552 millones de euros (758.448.000 usD) la realización de múltiples proyectos y actividades transfronterizas en las áreas fronterizas hispano-portuguesas (ARFE, 1997). Por su parte, interreg iI (2000-2006) dispuso 807 millones de euros (1.108.818.000 millones de dólares estadunidenses) para el financiamiento de actividades transfronterizas (Mora, Pimienta y García, 2005). Por último, para el periodo 2007-2013, INTERREG IV invirtió 267.405.976 millones de euros (367.415.811 millones de dólares estadunidenses) en las actividades de cooperación transfronteriza luso-hispanas. El efecto inversor de tales programas se está dejando sentir de forma obvia en las comarcas fronterizas, sobre todo a nivel de infraestructuras viarias de transporte y comunicación, surgiendo nuevos puentes, carreteras, autopistas, vías férreas, telecomunicaciones o mejorándose y readaptándose los existentes.

${ }^{18}$ INTERREg se lanzó como INTERREG I para el periodo 1989-1993, continuó como INTERREG II en el periodo 1994-1999, INTERREG III en el periodo 2000-2006 y como INTERREG IV para el periodo 2007-2013.

${ }^{19}$ Programa específico de desarrollo rural y de zonas de montaña de la uE. 
Francisco José Calderón Vázquez / Repasando la frontera hispano-portuguesa

\section{La nueva política de cooperación transfronteriza en el contexto institucional de la UE: El POCTEP (2007-2013)}

A tenor de los párrafos anteriores, parece evidente la contribución de la política regional comunitaria ${ }^{20}$ en la superación de los obstáculos existentes a la cooperación transfronteriza luso-hispana. Dentro del panorama político-institucional de la Unión Europea, la cooperación transfronteriza, transnacional e interregional, aparece integrada dentro de la "nueva" política regional europea que, en términos operativos, plantea una simplificación de los antiguos objetivos de los Fondos Estructurales, que se van a ver reducidos a tres: 1) convergencia, 2) competitividad regional y empleo, y 3) cooperación territorial europea; este último engloba los tres ámbitos territoriales de cooperación (transfronterizo, interregional y transnacional) (Comisión Europea, 2007).

La cooperación transfronteriza cobra particular relevancia en el periodo de programación 2007-2013. Partiendo de la experiencia adquirida y de los logros de la iniciativa europea INTERREG, el nuevo diseño de la cooperación transfronteriza europea engloba, además de a las regiones de nivel III (Nomenclature des Unités Territoriales Statistiques [NUTS] III), situadas a lo largo de las fronteras terrestres interiores, a determinadas fronteras terrestres exteriores y, por último, a determinadas regiones situadas a lo largo de las fronteras marítimas (Rojo, 2009).

Siguiendo estas nuevas directrices, el Programa Operativo de Cooperación Transfronteriza Portugal-España 2007-2013, ${ }^{21}$ abarca un territorio compuesto por 17 NUT III fronterizos,,$^{22}$ que cubren una superficie de

${ }^{20}$ Planteándose como prioridad de política regional, la promoción de la cooperación territorial, focalizada en los aspectos de cohesión y cooperación territorial. El objetivo de la cooperación territorial adquiere especial relevancia en la nueva política de cohesión 2014-2020, en conexión con la importancia concedida a la cohesión territorial por parte del Tratado de Lisboa.

${ }^{21}$ Aprobado por la Comisión Europea el 25 de octubre de 2007, el POCTEP 2007-2013 promueve el desarrollo de las zonas fronterizas entre España y Portugal, reforzando las relaciones económicas y las redes de cooperación existentes entre las cinco áreas definidas en el programa.

${ }^{22}$ Las 17 NUT III fronterizas se dividen por ambos lados de la raya de la siguiente manera: Portugal (10): Minho-Lima, Cávado, Alto Trás-os-Montes, Douro, Beira Interior Norte, Beira Interior Sul, Alto Alentejo, Alentejo Central, Baixo Alentejo y Algarve; 
$136640 \mathrm{~km}^{2}$ (23.5\% del espacio ibérico) y una población de 5474225 habitantes (10\% de la población total de los dos estados) (Secretariado Técnico Conjunto [sTC], 2013).

A su vez, las 17 NUT III se distribuyen en áreas de cooperación definidas en cinco espacios geográficos: Región Norte-Comunidad Autónoma de Galicia; Región Norte-Comunidad Autónoma de Castilla y León; Región Centro-Comunidad Autónoma de Extremadura-Región de Alentejo; Región de Alentejo-Comunidad Autónoma de Andalucía-Región de Algarve (2013). Entre las prioridades marcadas por el programa pueden destacarse: el desarrollo integrado de recursos del patrimonio histórico y cultural, gestión urbana, gobierno electrónico, utilización conjunta de equipamientos colectivos, mejoras de las redes y servicios de transporte, y medio ambiente y energía de carácter transfronterizo, entre otras ${ }^{23}$ (STC, 2013).

\section{Reflexiones y conclusiones: Contradicciones, ambigüedades y voluntarismos, las sombras de un proceso}

¿Se puede desactivar una frontera? La cuestión no parece tener respuesta fácil. En el caso de las fronteras intraeuropeas comunitarias, se trata de "productos históricos vivos", cuya dimensión histórica, precisamente, les dota de un carácter estructural (y no coyuntural) que implica una fuerte inercia fronteriza, como si el trazado de la línea fronteriza sobre el mapa estuviera hecho con tinta indeleble, muy difícil de borrar.

En el caso de la frontera hispano-portuguesa, a partir de 1986 se está llevando a cabo un proceso de desactivación del hecho fronterizo, siguiendo las pautas de la narrativa transfronteriza europea inherente al proceso de integración comunitaria y a la construcción de la actual Unión Europea. Las coordenadas de dicho proceso integrador implicaban como conditio sine qua non la superación o remoción de los obstáculos existentes al mismo, constituyendo la neutralización de las fronteras interiores de la uE un campo de actuación básico. Por ello, el proceso de desactivación fronteriza

España (7): Pontevedra, Ourense, Zamora, Salamanca, Cáceres, Badajoz y Huelva.

${ }^{23}$ En el marco del poctep 2007-2013, se han aprobado en primera convocatoria, 81 proyectos de cooperación transfronteriza, que suponen una inversión total de 1795 M€, con una dotación de ayuda de la Unión Europea/FEDER de $1295 \mathrm{M}$. 
hispano-lusa ha sido impulsado desde las altas instancias institucionales europeas, desarrollándose desde la segunda mitad de los años ochenta gracias al empuje combinado de los procesos de inversión y capitalización propiciados por los fondos y programas comunitarios, particularmente INTERREG, que han desempeñado un papel clave como dinamizadores de procesos de inversión y acumulación de capital en los territorios fronterizos luso-hispanos. También resulta muy destacable el esfuerzo pro-cooperatio de las administraciones públicas en todos sus niveles, particularmente los locales y provinciales.

Aunque todavía podría resultar prematura una evaluación de lo realizado en las dos últimas décadas, se constata el desarrollo de toda una serie de iniciativas, proyectos y programas transfronterizos en los territorios fronterizos luso-hispanos.

Los resultados de tales iniciativas y esfuerzos parecen significativos, en términos de superación de los obstáculos y barreras existentes (más en las tangibles que en las intangibles), para una mayor integración socioeconómica luso-hispana de cara a la desactivación del hecho fronterizo (y de sus consecuencias), dado el carácter estructural e histórico de dicha problemática.

En este sentido, las evaluaciones de impacto realizadas (evidentemente parciales) (Márquez, 2010; Medeiros, 2009) muestran grandes avances en términos de infraestructuras viarias que favorecen la articulación territorial a nivel económico estatal, es decir, entre España y Portugal, pero no necesariamente la articulación transfronteriza rayana entre ambos lados de la frontera (Márquez, 2012). Tales avances viarios resultan muy visibles (y tangibles) tanto en los tramos litorales de la frontera (especialmente en el tramo galaico, entre las regiones de Minho (Portugal) y Galicia (España) y, en menor medida, en el tramo sureño entre el Algarve (Portugal) y Andalucía (España), como en los grandes ejes viarios muy reforzados por la inversión de los fondos comunitarios, particularmente el eje BadajozElvas, si bien todavía están pendientes las articulaciones ferroviarias modernas y de alta velocidad (Medeiros, 2009).

Sin embargo, en otros tantos aspectos, los resultados aún sugestivos resultan ambiguos, ya en cuanto a la desactivacion fronteriza, ya en cuanto a la profundizacion cultural y humana de las interacciones (bastante superficiales, enogastronomía, turismo, entre otras), por cuanto aún queda 
mucho por hacer en los campos administrativos, culturales, regulaciones locales y regionales, potenciación de las competencias de los Gabinetes de Iniciativas Transfronterizas (GIT), etcétera (Medeiros, 2009).

No puede obviarse que la frontera hispano-portuguesa surge como línea divisoria, muy clara, entre España y Portugal, afianzándose a través de los siglos, desempeñando un papel clave en el proceso de generación de la identidad nacional portuguesa, tanto en términos lingüísticos y culturales como emocionales y de construcción social, condicionando mucho tanto la visión del "otro" como su "percepción", así como la generación de abundantes clichés y estereotipos. Esa desconfianza portuguesa hacia lo español se concretiza con perfección en frases típicas del refranero portugués como De Espanha, ne bom ventos, ne bom casamentos.

Esa divisoria cultural y social ha condicionado grandemente las interacciones fronterizas entre ambos lados de la "Raya Ibérica". En este sentido, las hibridaciones y mestizajes, muy frecuentes en otras fronteras europeas, en el caso luso-hispano resultan relativamente escazas, territorialmente circunscritas a puntos muy concretos de la línea fronteriza y de escasa importancia en términos geográficos y poblacionales, caso de las Falas, los Povos Promiscuos y el Couto Misto.

Asimismo, la presencia de comunidades históricas luso hablantes en territorio español y viceversa, tiene más que ver con alteraciones y vicisitudes de la línea fronteriza (casos de los grupos luso parlantes de Olivenza, Táliga o San Felices de los Gallegos) que con opciones o decisiones voluntarias de dichas comunidades. Igualmente, en términos cualitativos las hibridaciones hispano-portuguesas parecen más referidas a situaciones de ambigüedad por indefinición, por encima de cualquier otra circunstancia. De ahí que tengan un carácter más residual, de curiosidad histórica, cultural o antropológica.

En cuanto a las interacciones económicas tradicionales, las lícitas han tenido poca relevancia limitándose al pequeño comercio fronterizo. Por el contrario, las ilícitas (contrabando y otros tráficos ilegales) han tenido una importancia muy significativa, posiblemente más social que económica, pero al estar basadas en la mutua complicidad, tener mucho que ver con la necesidad y al desarrollarse de manera "invisible" y "silenciosa", han tenido poco reflejo en la construcción social, reforzándose la frontera en el imaginario social. 
La presencia de tan importantes e históricas cortapisas no planteaba como fácil el desarrollo y la cooperación transfronteriza para el caso de la Raya Ibérica. Sin embargo, las iniciativas y proyectos transfronterizos se han ido abriendo paso, abarcando cada vez más campos de actuación y, lo que es más importante, convirtiéndose en parte del panorama cotidiano de las tierras fronterizas, habituando a personas, empresas e instituciones al contacto permanente y cotidiano con el otro lado, combinando esfuerzos con los "otros" para mejorar el bienestar común, ampliándose el horizonte de acción de las poblaciones fronterizas, de modo que su país ya no termina en la frontera, sino que se extiende allende el confín.

En este contexto de dinamismo transfronterizo, las dificultades fiscales y financieras de los Estados ibéricos, en particular los presupuestos contractivos (y los subsiguientes recortes en el gasto público), y la enorme dependencia de la cooperación transfronteriza de la disponibilidad de Fondos Estructurales comunitarios (cuyos volúmenes financieros parecen menguar en los últimos ejercicios), podrían tener un efecto letal sobre las iniciativas transfronterizas luso-hispanas, por lo que se hace - a todas luces - necesario un compromiso tanto a escala nacional como europea, a favor de dar continuidad a los impulsos y pulsiones a favor de la cooperación transfronteriza puesto que un corte en el fluido inversor público (derivado de las políticas contractivas impulsadas por la propia Comisión Europea) podría generar un efecto blackout demoledor para muchos proyectos e iniciativas de cooperación transfronteriza lusohispana, con el riesgo cada vez más visible de que se pierdan (porque no se puedan consolidar) los avances tan arduamente conseguidos en estas últimas décadas.

\section{Bibliografía}

Antunes, M. D. (2008). Fronteras estatales y relaciones sociales en la frontera hispano-portuguesa. El caso de Barrancos y Oliva de la Frontera. Gazeta de Antropología, (24), 24-52. Recuperado de: <www.ugr.es/ pwlac/G24_52 MariaDulce_Antunes_Simoes.html>

Asociación de las Regiones Fronterizas Europeas (ARFE) (1997). Documento de trabajo sobre la iniciativa INTERREG de la UE y sus futuros desarrollos, diciembre. Recuperado de: <http://www.aebr.eu/files/publications/interreg_97.es.pdf> 
Bradshaw, R. y Linares, R. (1999). Fronteras: Una visión teórica en el mundo contemporáneo. Aldea Mundo. Revista sobre Fronteras e Integración, (7), 14-19. Recuperado de: < http://www.comunidadandina.org/bda/docs/VE-INT-0009. $\operatorname{pdf}>$

Cabanas, A. M. (2006a). Carregos: Contrabando na Raia Central. Lisboa: Artemágica.

Cabanas, A. M. (2006b). Estudo do Contrabando na Raia Central. Actas do IV Congresso Português de Sociologia. Coimbra, Portugal. Recuperado de: <http:// www.aps.pt/cms/docs_prv/docs/DPR462de91a46ce1_1.pdf>

Cáceres, R. y Valcuende del Río, J. M. (1996). Hacer la carrera de Portugal, el trasperlo y otras formas de contrabando. En P. Palenzuela (Coord.), Actas del VII Congreso de Antropología del Estado Español (pp.137-149). Zaragoza: Antropología del Trabajo.

Cairo, H. (2001). Territorialidad y fronteras del Estado nación: Las condiciones de la política en un mundo fragmentado. Revista Política y Sociedad, 36, 29-38.

Cairo, H. (2009). De las fronteras de la primera modernidad a las de la condición postmoderna: El laboratorio ibérico. En H. Cairo, P. Godinho y X. Pereiro (Coords.), Portugal e Espanha entre discursos de centro e praticas de fronteira (pp. 33-51). Lisboa: Colibrí.

Cairo, H., Godinho, P. y Pereiro, X. (Coords.) (2009). Portugal e Espanha entre discursos de centro e praticas de fronteira. Lisboa: Colibrí, Instituto de Estudios de Literatura Tradicional.

Calderón, F. J. (2010). La Raya luso-hispana, una frontera en transición. En J. A. Márquez (Coord.), Actas del Congreso Internacional Cooperación transfronteriza Andalucía-Algarve-Alentejo (pp. 41-54). Huelva: Servicio de Publicaciones de la Universidad de Huelva.

Caramelo, S. (2002). Fronteiras e regioes fronteiriças na Uniao Europeia: Procesos, dinamicas e singularidades do caso luso-espanhol. En M. Tavares (Coord.), Identidade Europeia e Multiculturalismo (pp. 323-348). Coimbra: Quarteto Editora.

Carrasco, J. M. (1997). Hablas y dialectos portugueses o galaico-portugueses en Extremadura. Anuario de Estudios Filológicos, 20, 61-79.

Carrasco, J. M. (2001). La frontera lingüística hispano-portuguesa en la Provincia de Badajoz. Revista de Filología Románica, 18, 139-158.

Castro, M. (2011). A fronteira Portugal Espanha após 1995. Profforma, (05), diciembre. Recuperado de: <http://www.cefopna.edu.pt/revista/revista_05.htm>

Christaller, W. (1966). Central Places in Southern Germany. Englewood Cliffs, Nueva Jersey: Prentice Hall.

Comision Europea (СE) (2007). La politique de cohesión 2007-2013. Commentaires et textes officiels. Luxemburgo: Office des Publications Officielles des Communautés Européennes. 
Consejo de Europa (1980). Convenio Marco Europeo sobre Cooperación Transfronteriza entre Comunidades o Autoridades Territoriales (CMECT). Recuperado de < http:// www.interior.gob.es/web/servicios-al-ciudadano/normativa/acuerdos-y-convenios/convenio-marco-de-21-de-mayo-de-1980>

Corrales, I. (2006). Extremadura y Portugal: El Gabinete de Iniciativas Transfronterizas. Recuperado de < http://www.dip-badajoz.es/publicaciones/reex/rcex_3_2006/ estudios_12_rcex_3_2006.pdf>

Cruz-Sagredo, J. D. (2010). Contrabandistas somos y en el descamino nos encontraremos: El contrabando tradicional y otras formas de subsistencia en las fronteras ibéricas. Especial referencia a la raya hispano-lusa. Valladolid: Junta de Castilla y León, Gabinete de Iniciativas Transfronterizas.

Curiosidades fronteiriças: Casas de la Duda, Pino (Valência de Alcântara) (2012). [Mensaje de un blog]. Recuperado de <http://historiasdaraia.blogspot. it/2012/02/curiosidades-fronteiricas-casas-de-la.html>

De la Fuente, R. (2009). Una aproximación al análisis del discurso de la re significación de la frontera en la Unión Europea. En H. Cairo, P. Godinho y X. Pereiro (Coords.), Portugal e Espanha: Entre discursos de centro e práticas de frontera (pp. 115-130). Lisboa: Colibrí.

De la Macorra y Cano, L. F. (2005). Caracterización económica de la Raya Ibérica. Economía de las Comunidades Autónomas: La Raya Ibérica: Centro-sur, [Monografía], Papeles de Economía Española, (21), 15-30.

De la Montaña, J. L. (2005). El comercio en la frontera castellano-portuguesa: El ámbito extremeño (siglos XIII-Xv). La España Medieval, 28, 81-96.

Donnan, H. (1998). Borders Frontiers of Identity, Nation and State. Cambridge: University Press.

Donnan, H. y Wilson, T. M. (1994). Border Approaches: Anthropological Perspectives on Frontiers. Lanham: University Press of America.

Donnan, H. y Wilson, T. M. (1999). Borders: Frontiers of Identity, Nation and State. Oxford: Berg.

Duarte, L. M. (1998). Contrabandistas de gado e "Passadores de cousas defesas" para Castela e "Terra de Mouros". Historia Revista da Faculdade de Letras, 1(15), 451-474.

Ferrer-Gallardo, X. (2007). Border acrobatics between the European Union and Africa. The management of sealed-off permeability on the borders of Ceuta and Melilla. En E. Brunet-Jailly (Ed.), Borderlands: Comparing border security in North America and Europe (pp. 75-96). Ottawa: University of Ottawa Press.

Ferrer-Gallardo, X. (Marzo, 2008). The Spanish-Moroccan border complex: Processes of geopolitical, functional and symbolic rebordering. Political Geography, 27(3), marzo, 301-321.

Fonte, R. (2007). Amistades necesarias. Recuperado de: < http://cvc.cervantes.es/ lengua/anuario/anuario_0607/pdf/miradas_04.pdf > 
Foucher, M. (1991). Fronts et frontiers. Un tour de monde geopolitique. París: Faeard.

García, J. M. (1998). La frontera luso-española: historia y realidad. Revista del Ministerio Fiscal, (5), 161-174.

García, L. M. (1988). La frontera hispano-lusa en la provincia de Ourense. Ourense: Museo Arqueolóxico Provincial.

García, S. y Mora, J. (2005). Estudio de la iniciativa INTERREG III A España-Portugal. Recuperado de: <http://www.apgeo.pt/files/docs/CD_X_Coloquio_Iberico_ Geografia/pdfs/008.pdf>

Gaspar, J. (1993). As regioes portuguesas. Lisboa: Ministerio do Planeamento.

Hinojosa, J. (1998). El comercio y la frontera en la Península Ibérica en los siglos medievales. Actas iI Estudios de frontera. Actividad y vida en la frontera, Diputación Provincial de Jaén, España.

Kavanagh, W. (2009). Se puede quitar la puerta, pero se queda el marco. Identidades, cambiantes y no cambiantes, en las fronteras europeas. En Portugal e Espanha entre discursos de centro e praticas de frontera (pp. 155-172). Lisboa: Colibrí.

Kavanagh, W. (2011). Identidades en la frontera luso-española. Geopolítica(s), 2(1), 23-50.

Kolossov, V. O’Loughlin, J. (1998). New borders for new world orders: Territorialities at the fin-de-siecle. GeoJournal, 44(3), 259-273.

Leyendas y curiosidades de La Raya (23 de octubre de 2005). Diario el Periódico de Extremadura. Recuperado de: <www.elperiodicoextremadura.com/noticias/ noticia.asp?pkid $=201127>$

Lezzi, M. (1994). Competition-cooperation: A creative interplay of border regions in economic development planning and in transborder institutions. En W. Gallusser (Ed.), Political boundaries and coexistence. Proceedings of the IGU-Symposium Basle/Switzerland (pp. 322-332). Berna, Suiza: Peter Lang.

Lofgren, O. (2008). Regionauts: The transformation of cross-border regions in Scandinavia. European Urban and Regional Studies, 15(3), 195-209.

López, L. (2005). La Raya Ibérica como espacio de atracción y cooperación. Economía de las Comunidades Autónomas: La Raya Ibérica: Centro-sur, [Monografía], Papeles de Economía Española, (21), 3-13.

Lösch, A. (1967). The Economics of Location. New Haven: Yale University Press.

Márquez, J. A. (2010). Deconstrucción y articulación territorial de la frontera luso-andaluza. Cuadernos Geográficos de la Universidad de Granada, 47, 297316.

Márquez, J. A. (2012). El desencuentro entre la frontera y La Raya: El fracaso de las políticas territoriales de desarrollo en la eurorregión Andalucía-Algarve-Alentejo. España: Academia Andaluza de Ciencia Regional, marzo. Recuperado de: $<$ http://www.acacr.es/discursos/E1\%20desencuentro\%20entre\%20la\%20 frontera\%20y\%20la\%20raya.pdf> 
Francisco José Calderón Vázquez / Repasando la frontera hispano-portuguesa

Martín, J. L. (2003). La tierra de las “contiendas”, notas sobre la evolución de la raya meridional en la Edad Media. Norba. Revista de Historia, 16(1), 277-293.

Medeiros, E. J. (2009). A cooperação transfronteiriça na Raia Ibérica: Uma síntese geográfica dos impactes territoriais do INTERREG-A. Recuperado de: <http://www. ccmar.ualg.pt/gostodofrio/ct/pub_ceg_em.pdf>

Medina, E. (2004). Contrabando en la frontera de Portugal: Orígenes, estructuras, conflicto y cambio social. Tesis doctoral. Recuperada de: <http://eprints.ucm.es/ tesis/cps/ucm-t25310.pdf>

Medina, E. (2006). Orígenes históricos y ambigüedad de la frontera hispanolusa (La Raya). Recuperado de: </www.dip-badajoz.es/publicaciones/reex/ rcex_2_2006/estudios_11_rcex_2_2006.pdf >

Medina, E. (2008). Trabajadores fronterizos y transfronterizos en España y Portugal a lo largo de la historia. Revista de Estudios Extremeños, 64(1), 6188. Recuperado de: <http://dehesa.unex.es:8080/xmlui/bitstream/hand le/10662/1011/0210-2854_64_61.pdf?sequence $=1>$

Medina, E. (2009). ...Y llegó el tiempo en que acabó la frontera: Inicios y desarrollo de la cooperación transfronteriza entre las comarcas del noroeste de Extremadura (España) y la Beira Interior Sul (Portugal). En H. Cairo, P. Godinho y X. Pereiro (Coords.), Portugal e Espanha entre discursos de centro e praticas de fronteira (pp. 257-290). Lisboa: Colibrí.

Melón, M. Á. (1999). Hacienda, comercio y contrabando en la frontera con Portugal. Cáceres: Ficón.

Mora, J., Pimienta, M. y García, S. (2005). La iniciativa comunitaria INTERreg III en España. Boletín de la Asociación de Geógrafos Españoles, (39), 267-284.

Newman, D. (1998). Boundaries, territories and postmodernism. Towards shared or separate spaces? Documento presentado en la $5^{\text {th }}$ International Conference of the International Boundaries Research Unit: Borderlands Under Stress, Durham, Inglaterra.

Newman, D. y Paasi A. (1998). Fences and neighbours in the postmodern world: Boundary narratives in political geography. Progress in Human Geography, 22(2), 186-207.

Pinheiro, D. E. (2004). Comércio é comércio... ou não? Recuperado de: < http://www. cei.pt/pdfdocs/Delfina-final-4marco.pdf>

Pires, I. M. y Pimentel, D. (2004). Revisitando a região transfronteiriça ibérica: Potencialidades e estrangulamentos no novo contexto de integração ibérica. V Congresso da Geografia Portuguesa. Portugal: Territórios e protagonistas, Associação Portuguesa de Geógrafos, Lisboa, Portugal. Recuperado de: <http://www. apgeo.pt/files/docs/CD_V_Congresso_APG/web/_pdf/D7-8_14Out_Iva\%20 Pires-Dulce\%20Pimentel.pdf> 
Pires, I. y Teixeira, J. A. (2002). A integraçao do mercado iberico: Novos ventos que casamento? En C. Cavaco (Coord.), Repensar Portugal na Europa, perspectivas de um país periferico (pp. 301-331). Lisboa: Universidade de Lisboa.

Pires, I. y Teixeira, J. A. (2003). Portuguese border regions: Will they be able to adapt to a global economy? Documento presentado en la Conferencia da RSA Reiventing Regions in the Global Economy, Pisa, abril.

Reis, C. (2007). Bons ventos e costas voltadas. Reflexoes tempestivas sobre alguns lugares comuns. En Á. Marcos de Dios (Coord.), Aula ibérica: Actas de los congresos de Evora y Salamanca (pp. 33-42).

Rojo, A. (2009). La cooperación transfronteriza y sus consecuencias: Hacia la reestructuración territorial en Europa. Investigaciones Regionales, (18), 141154.

Rubio, E. (2007). Viaje por las 'andorras' extremeñas. Diario Hoy Digital, 9 de diciembre. Recuperado de: <http://www.hoy.es/20071209/regional/viajeandorras-extremenas-20071209.html>

Secretariado Técnico Conjunto (STC). (2013). Programa Operativo de Cooperación Transfronteriza Portugal-España (2007- 2013): Documento final para aprobación por la Comisión Europea. Recuperado de: < http://www.poctep. eu/index.php? $m o d u l o=$ presentacion\&id_area $=13>$

Sideway, J. D. (2001). Rebuilding bridges: A critical geopolitics of Iberian transfrontier cooperation in a European context. Environment and Planning D: Society and Space, 19(6), 743-778.

Tamames, R. (1994). La Unión Europea. Madrid: Alianza Universidad.

Taylor, P. (1994). The state as container: Territoriality in the modern world-system. Progress in Human Geography, 18(2), 151-162.

Taylor, P. (1995). Beyond containers: Internationality, interstateness, interterritoriality. Progress in Human Geography, 19 (1), 1-15.

Un país en cada acera (2006). Diario El País, 13 deagosto. Recuperado de: <elviajero. elpais.com/articulo/viajes/pais/acera/elpviavia/20060812elpviavje_3/Tes>

United Nations (1982). Treaty series. Treaty on boundaries between Spain and Portugal from the mouth of the Minho River to the junction of the river Caya with the Guadiana, 1288(906), 244-274. Recuperado de: <http://untreaty. un.org/unts/60001_120000/9/37/00017843.pdf>

Val Valdivieso, M. I. (1987). Mercaderes portugueses en Medina del Campo. Actas II Jornadas Luso-Espanholas de Historia Medieval, Instituto Nacional de Investigaçao Científica, Porto, Portugal.

Van Houtum, H. y Struver, A. (2002). Borders, strangers, doors and bridges. Spaces \& Polity, 6(2), 141-146. 
